\title{
Paraneoplastic Dermatomyositis in Hepatocellular Carcinoma with Colonic Perforation: A Case Report
}

\author{
Naoteru Miyata ${ }^{a}$ Katsura Emoto $^{b}$ Yoshiaki Dei $^{c} \quad$ Kazuhiro Tomiyasu $^{d}$ \\ Ryoko Ishiyama $^{a}$ Tomofumi Horie ${ }^{a}$ Gen Sakai ${ }^{a}$ Toshiyuki Tahara ${ }^{a}$ \\ ${ }^{a}$ Department of Gastroenterology, Saiseikai Utsunomiya Hospital, Tochigi, Japan; \\ ${ }^{b}$ Department of Pathology, Saiseikai Utsunomiya Hospital, Tochigi, Japan; ' Department of \\ Rheumatology, Saiseikai Utsunomiya Hospital, Tochigi, Japan; ${ }^{d}$ Department of Neurology, \\ Saiseikai Utsunomiya Hospital, Tochigi, Japan
}

\section{Keywords}

Dermatomyositis · Hepatocellular carcinoma $\cdot$ Colonic perforation $\cdot$ Case report

\begin{abstract}
Background: Dermatomyositis (DM) is an autoimmune disease characterized by cutaneous Gottron papules, heliotrope rash, and proximal myopathy. It may also present as a paraneoplastic syndrome that can complicate a variety of different cancers, such as lung, cervical, and breast cancer. However, the association with hepatocellular carcinoma (HCC) is extremely rare. Moreover, to our knowledge, there are no previous reports of colonic perforation following steroid pulse treatment for a DM patient. Case Summary: A 61-year-old male complained of a skin rash that began in his neck and spread to his face and abdomen. On physical examination, the patient was also found to have symmetrical proximal muscle weakness, abdominal pain, heliotrope rash in the periorbital skin, and poikiloderma on his face and abdomen. Serum level of muscle enzymes was remarkably increased. Muscle examination revealed symmetrical proximal weakness. The diagnosis of DM was made, and steroid treatment was started for symptomatic relief. A search for causative malignancy revealed HCC. Despite steroid therapy for DM, his symptoms did not improve. Additionally, C-reactive protein elevation was seen along with severe abdominal pain on day 14 of admission. Shortly after this, the patient died of septic shock due to suppurative peritonitis after perforation of
\end{abstract}


Miyata et al.: Paraneoplastic Dermatomyositis in Hepatocellular Carcinoma with Colonic Perforation: A Case Report

the ascending colon. Conclusion: Here, we present a rare case of DM caused by nonhepatitis-associated advanced HCC with colonic perforation. The cause of colonic perforation is still unclear. This case demonstrates the need to carefully monitor abdominal pain in DM patients as symptoms can be masked by steroid therapy.

\section{Background}

Dermatomyositis (DM) is a rare autoimmune disease which causes an idiopathic inflammatory myopathy with cutaneous manifestations. DM is also a known paraneoplastic syndrome that can complicate a variety of different neoplasms, such as lung, cervical, and breast cancers $[1,2]$. The association with hepatocellular carcinoma (HCC) is extremely rare, and most cases occur in association with viral hepatitis-associated HCC [3]. Here, we report a case of a patient with DM and non-hepatitis-associated advanced HCC who developed a colonic perforation.

\section{Case Report}

A 61-year-old male with a history of peptic ulcer disease and hemorrhoids presented at the dermatology clinic with the chief complaint of a rash on the back of his neck that had developed 3 weeks earlier as well as muscle pain. In the clinic, the rash was found to have spread to his face and abdomen; the patient was also found to have bilateral muscle weakness and abdominal pain.

This constellation of symptoms prompted a referral to rheumatology with a presumptive diagnosis of DM. There was no family history of autoimmune disease or malignancy. At the time of rheumatology assessment, his physical examination was significant for a heliotrope rash in the periorbital skin, Gottron papules on the metacarpophalangeal joints, and poikiloderma on the posterior neck and abdomen. Muscle examination revealed symmetric proximal muscle weakness.

Laboratory studies showed AST $311 \mathrm{U} / \mathrm{l}$, ALT $142 \mathrm{U} / \mathrm{l}$, creatine kinase 7,400 U/l, aldolase $39.5 \mathrm{IU} / \mathrm{l}$, and negative anti Jo-1 antibody. Antinuclear antibodies were negative (1:40). The patient was serologically negative for hepatitis $B$ and $C$ viruses. The serum PIVKA-II and AFP levels were significantly elevated at $176,000 \mathrm{mAU} / \mathrm{ml}$ and above 1,000 $\mathrm{ng} / \mathrm{ml}$, respectively. A computed tomography (CT) scan showed a large hypoechoic hepatic mass in the left lateral lobe which appeared to attach to the diaphragm. Several small masses in the right lobe of the liver and para-aortic lymph node enlargement were also seen (fig. 1a, b). The tumor markers and imaging were suggestive of metastatic HCC. Electromyography of the right biceps brachii muscle and extensor digitorum muscle showed fibrillation and lowamplitude voltage, consistent with DM. The patient refused a muscle biopsy during admission. The diagnosis of DM was established based on proximal muscular weakness, spontaneous muscle pain, positive elevated serum level of muscle enzymes, and positive electromyography findings.

After establishing this diagnosis, steroid therapy was started with $40 \mathrm{mg}$ of daily prednisolone. Treatment was not effective, and his muscle pain failed to improve despite increasing prednisolone to $80 \mathrm{mg} /$ day. Therapy was intensified to i.v. steroid pulse, consisting of 3 days of $1,000 \mathrm{mg} /$ day of methylprednisolone. Muscle pain and muscle enzymes improved transiently after the treatment. 


\section{Case Reports in Oncology}

\begin{tabular}{l|l}
\hline Case Rep Oncol 2016;9:547-553 \\
\hline DOI: 10.1159/000449370 & $\begin{array}{l}\text { C 2016 The Author(s). Published by S. Karger AG, Basel } \\
\text { www.karger.com/cro }\end{array}$ \\
\hline
\end{tabular}

Miyata et al:: Paraneoplastic Dermatomyositis in Hepatocellular Carcinoma with Colonic Perforation: A Case Report

On day 8 of admission, the gastroenterology service was consulted for evaluation of new-onset abdominal pain. The patient complained of moderate lower abdominal pain. Physical exam was reassuring without peritoneal signs. Supportive treatment for abdominal discomfort was provided with a 5-day course of butylscopolamine. Over this time period, the patient's pain did not improve, and an abdominal X-ray showed severe distention of the small intestine.

On day 14 of admission, a PET-CT was performed to assess the origin of the hepatic mass. Extraluminal air was incidentally found, with fluorodeoxyglucose accumulation in the ascending colon (fig. 2). The patient and his family refused further treatment. Unfortunately, the patient died due to suppurative peritonitis and septic shock.

An autopsy was performed. Histopathology of the left liver mass showed a trabecular and alveolar pattern with rich fibrous septa (fig. 1d), consistent with HCC with intrahepatic metastasis. Irregular size and degeneration of muscle fibers with infiltration of inflammatory cells were seen in the muscle autopsy, which was consistent with the diagnosis of DM (not shown).

\section{Discussion}

DM is an uncommon disease of the connective tissues characterized primarily by inflammation of the skin and muscle. It is also a known paraneoplastic syndrome that can affect $15-32 \%$ of patients with malignancies, such as lung, cervical, and breast cancer $[4,5]$. The association with HCC is extremely rare and in most cases occurs in association with viral hepatitis-associated HCC $[6,7]$. In this case, viral hepatitis was not detected in the patient. A large HCC was found in the left lobe with dissemination to the right lobe and para-aortic lymph nodes. HCC tumor markers were significantly elevated.

The mechanism of DM as a paraneoplastic syndrome is unclear. In the literature, a correlation between Mi-2 antibody, which is part of the nucleosome remodeling and deacetylase complex, and symptoms of DM is reported [8,9]. Toshikuni et al. [7] reported improvement of DM symptoms without corticosteroids after HCC resection, supporting the hypothesis that HCC can cause DM through a paraneoplastic mechanism.

In the present case, surgical treatment was not indicated as the patient had a large HCC in the left lobe with intrahepatic metastasis and para-aortic lymph node metastases. Sorafenib is the preferred treatment for HCC that cannot be surgically resected, but the patient's rapid deterioration impeded its use.

The reason for the intestinal perforation after steroid pulse treatment is an issue of debate. Previously, juvenile DM complicated with intestinal perforation has been reported [10]. To our knowledge, this is a rare case of colonic perforation after steroid treatment in an adult with DM. It is unclear how the colonic perforation occurred in this patient. One possibility is that colonic perforation was caused by vasculitis and vessel occlusion, which is often seen in DM and carries a risk of bowel perforation [11]. Vasculitis of the gastrointestinal tract is a life-threatening complication. It may vary from segmental bowel edema to ulcerations, gangrene, and perforation [12]. However, the clinical findings may be masked by corticosteroid therapy even in the presence of bowel perforation, as the lesion may be very small, retroperitoneal, self-sealed, or well contained by the adjacent structures [13]. Surgical treatment is not standardized because of the rarity and variety of the gastrointestinal DM presentations. Bowel sounds and muscle guarding are unreliable physical signs. Consequently, bowel gangrene and perforation may occur and result in death. The cause of perforation 


\section{Case Reports in Oncology}

Miyata et al:: Paraneoplastic Dermatomyositis in Hepatocellular Carcinoma with Colonic Perforation: A Case Report

could not be determined by autopsy due to the presence of severe peritonitis. The submucosal layer of the colon showed mild fibrosis and congestion; however, few findings of vasculitis were observed (fig. 3).

Another possibility is that colonic perforation occurred as a consequence of steroid pulse treatment. A previous report described that massive steroid use may increase the risk of intestinal perforation [14]. The authors concluded that massive steroid therapy enhanced fibrotic changes of the intimal tissue, which could consequently cause intestinal perforation due to vascular obstruction. Moreover, corticosteroids also disturb intestinal repair and mucosal defense by inhibiting prostaglandin synthesis. Distorted mucosal surfaces are prone to bacterial colonization, especially if the patient has diverticular disease. However, in this case, no diverticulum was found in the autopsy.

\section{Conclusions}

Here, we report a case of DM in the context of non-hepatitis-associated HCC that was further complicated by colonic perforation after steroid pulse treatment. Although there are several markers produced by malignancy, they cannot predict the severity of DM symptoms. HCC should be resected in early stages to relieve the symptoms of DM. There is no doubt that careful observation after steroid pulse treatment for DM patient is warranted. Intestinal perforation should be included in the differential diagnosis of DM presenting with abdominal complaints.

\section{Statement of Ethics}

Written informed consent was obtained from the patient's wife for publication of this case report. Approval by the ethics committee of Saiseikai Utsunomiya Hospital, Tochigi, Japan (No. 2016-07), was also obtained.

\section{Author Contributions}

Clinical data were collected by R.I., T.H., and N.M. The first draft of the manuscript was written by N.M. Agreement with manuscript results and conclusions was provided by N.M., Y.D., and T.T. Neurological assessment was performed by K.T. Critical revisions and an approved final draft were done by N.M. All authors reviewed and approved of the final manuscript.

\section{Disclosure Statement}

The authors declare that they have no competing interests. 


\section{Case Reports in Oncology}

\begin{tabular}{l|l}
\hline Case Rep Oncol 2016;9:547-553 \\
\hline DOI: $10.1159 / 000449370$ & $\begin{array}{l}\text { (c) 2016 The Author(s). Published by S. Karger AG, Basel } \\
\text { www.karger.com/cro }\end{array}$ \\
\hline
\end{tabular}

Miyata et al.: Paraneoplastic Dermatomyositis in Hepatocellular Carcinoma with Colonic Perforation: A Case Report

\section{References}

1 Barnes BE, Mawr B: Dermatomyositis and malignancy. A review of the literature. Ann Intern Med 1976;84:68-76.

2 Requena C, Alfaro A, Traves V, Nagore E, Llombart B, Serra C, Martorell A, Guillén C, Sanmartín O: Paraneoplastic dermatomyositis: a study of 12 cases. Actas Dermosifiliogr 2013;105:675-682.

-3 Fiore G, Giacovazzo F, Giacovazzo M: HCV and dermatomyositis: report of 5 cases of dermatomyositis in patients with HCV infection. Riv Eur Sci Med Farm 1996;18:197-201.

$\checkmark 4$ Sigurgeirsson B, Lindelöf B, Edhag O, Allander E: Risk of cancer in patients with dermatomyositis or polymyositis. A population-based study. N Engl J Med 1992;326:363-367.

-5 Hill CL, Zhang Y, Sigurgeirsson B, Pukkala E, Mellemkjaer L, Airio A, Evans SR, Felson DT: Frequency of specific cancer types in dermatomyositis and polymyositis: a population-based study. Lancet 2001;357:96-100.

-6 Kee S-J, Kim T-J, Lee S-J, Cho Y-N, Park S-C, Kim J-S, Kim J-C, Kang H-S, Lee S-S, Park Y-W: Dermatomyositis associated with hepatitis B virus-related hepatocellular carcinoma. Rheumatol Int 2009;29:595-599.

7 Toshikuni N, Torigoe R, Mitsunaga M, Omoto A, Nakashima K: Dermatomyositis associated with hepatocellular carcinoma in an elderly female patient with hepatitis $\mathrm{C}$ virus-related liver cirrhosis. World J Gastroenterol 2006;12:1641-1644.

8 Targoff IN, Reichlin M: The association between Mi-2 antibodies and dermatomyositis. Arthritis Rheum 1985;28:796-803.

-9 Mierau R, Dick T, Bartz-Bazzanella P, Keller E, Albert ED, Genth E: Strong association of dermatomyositis-specific Mi-2 autoantibodies with a tryptophan at position 9 of the HLA-DR beta chain. Arthritis Rheum 1996;39:868-876.

-10 Singh S, Suri D, Aulakh R, Gupta A, Rawat A, Kumar RM: Mortality in children with juvenile dermatomyositis: two decades of experience from a single tertiary care centre in North India. Clin Rheumatol 2014;33:1675-1679.

-11 Venditti D, Balassone V, Ielpo B, Buonomo 0, Petrella G: Bowel perforations in a patient affected by Churg-Strauss syndrome under high-dose steroid treatment: will alternative drugs reduce risk of surgery? Rheumatol Int 2011;31:1239-1241.

12 Villa R, Costa S, Focchi S, Corbellini C, Vigorelli M, Avesani EC: Successful open abdomen treatment for multiple ischemic duodenal perforated ulcers in dermatomyositis. World J Emerg Surg 2014;9:48.

13 Smerud MJ, Johnson CD, Stephens DH: Diagnosis of bowel infarction: a comparison of plain films and CT scans in 23 cases. AJR Am J Roentgenol 1990;154:99-103.

14 Kaya B, Aras 0, Bat O, Bulut NE, Memisoglu K: Steroid-induced sigmoid diverticular perforation in a patient with temporal arteritis: a rare clinical pathology. Clin Med Insights Pathol 2012;5:11-14. 


\section{Case Reports in Oncology}
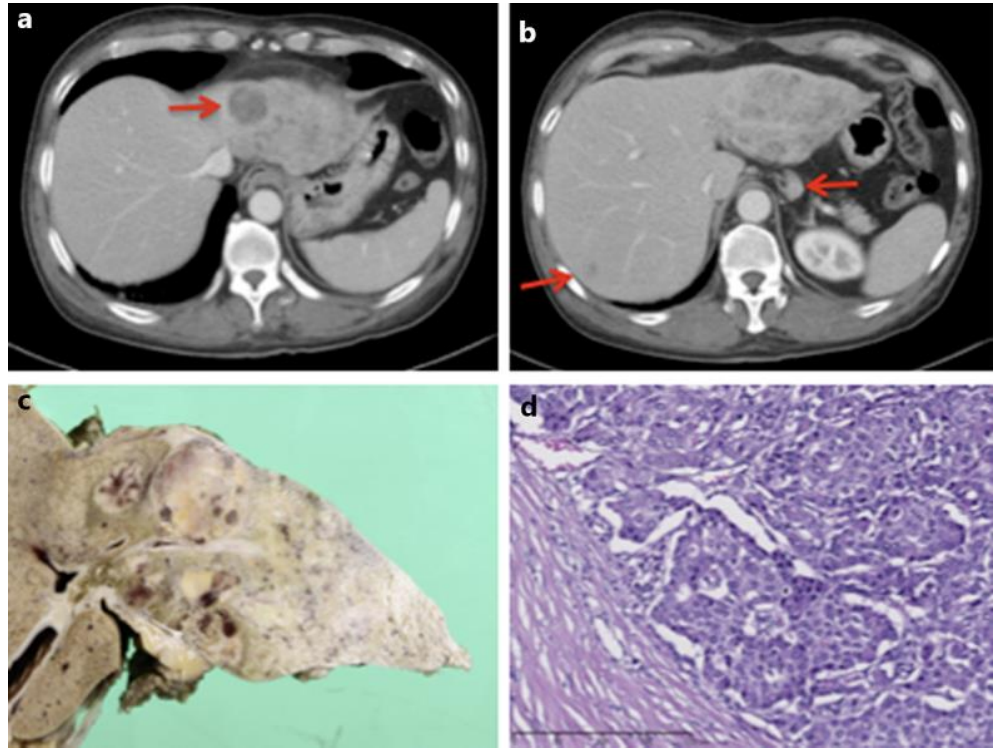

Fig. 1. Contrast-enhanced CT and histopathology of HCC. a Ill-defined, heterogeneous enhanced mass with necrosis (arrowhead) in the left lobe attached to the diaphragm. b Intrahepatic metastasis and para-aortic lymph node enlargement (arrowhead). c Macroscopically, the tumor is diffusely observed in the left lobe, and some intrahepatic metastases are seen. $\mathbf{d}$ HCC cells show a trabecular and alveolar pattern with rich fibrous septa. 


\section{Case Reports in Oncology}

\begin{tabular}{l|l}
\hline Case Rep Oncol 2016;9:547-553 \\
\hline DOI: 10.1159/000449370 & $\begin{array}{l}\text { @ 2016 The Author(s). Published by S. Karger AG, Basel } \\
\text { www.karger.com/cro }\end{array}$ \\
\hline
\end{tabular}

Miyata et al.: Paraneoplastic Dermatomyositis in Hepatocellular Carcinoma with Colonic Perforation: A Case Report
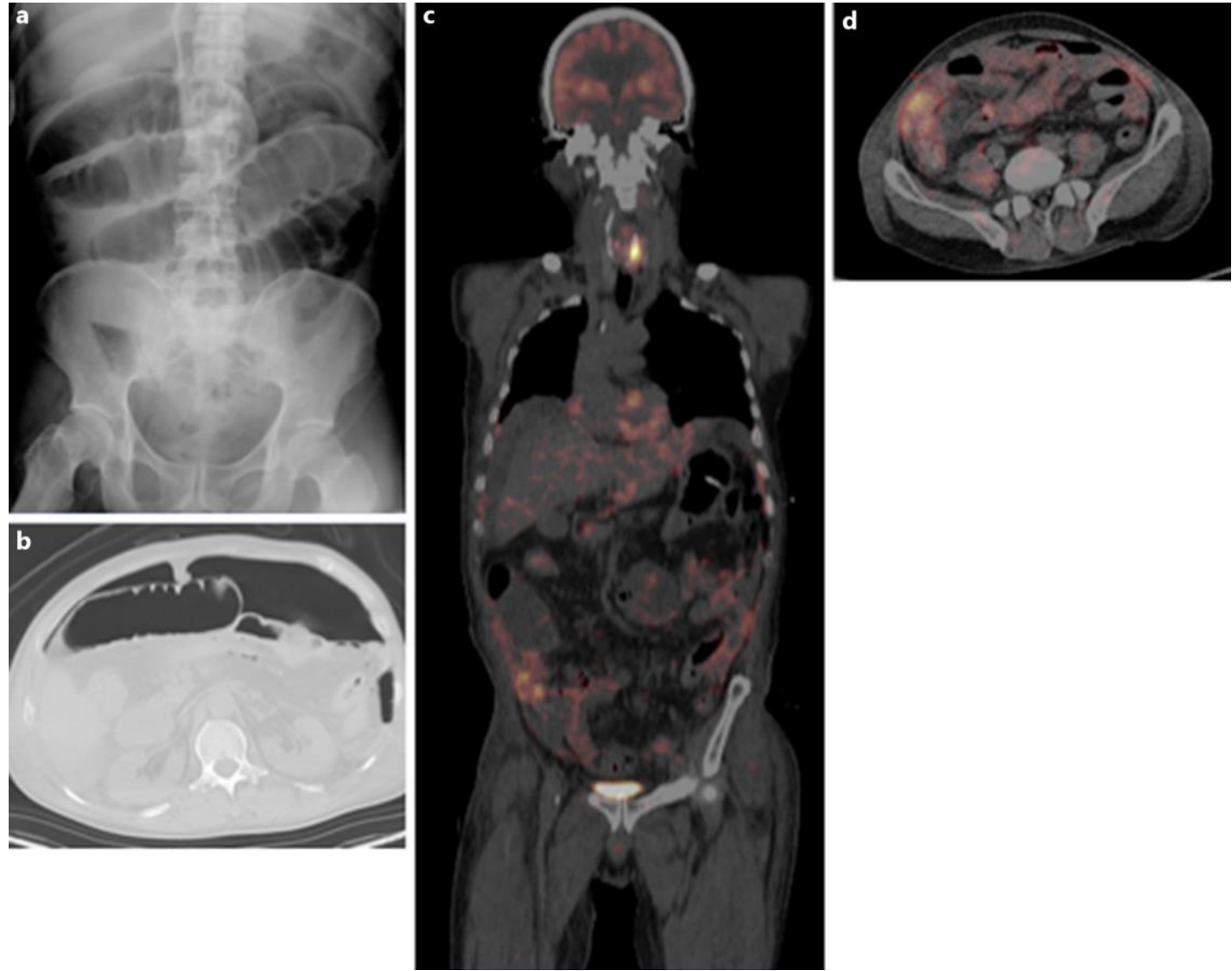

Fig. 2. Radiological findings. a Abdominal plain radiograph reveals dilation of the intestine. $\mathbf{b}$ Transverse plain CT showing free air. c, d PET-CT showing fluorodeoxyglucose accumulation in the ascending colon.
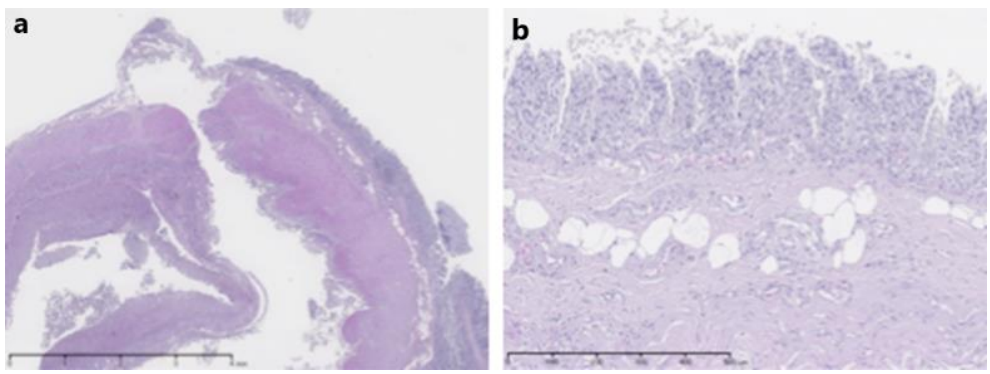

Fig. 3. Histopathology of the colon. a Suppurative peritonitis presents as a severe infiltration of inflammatory cells in the serosal layer. $\mathbf{b}$ The colon shows autolytic or/and atrophic changes in the mucosal layer and mild fibrosis in the submucosal layer. No deterministic vasculitis can be observed. 